\title{
OS MEIOS CONSENSUAIS, ENTRE A CRÍTICA DO PROCESSO E A CONVICÇÁO DAS POTENCIALIDADES DA JUSTIÇA
}

\author{
CONSENSUS MEANS, BETWEEN PROCESS CRITICISM AND \\ CONVICTION OF JUSTICE'S POTENTIALITIES
}

\author{
Sergio de Souza Salles ${ }^{\mathrm{I}}$ \\ Geovana Faza da Silveira Fernandes ${ }^{\mathrm{II}}$ (i)
}

\begin{abstract}
I Universidade Católica de Petrópolis,
Petrópolis, RJ, Brasil. Doutor em Filosofia. E-mail: sergio.salles@ucp.br

II Subseção Judiciária de Juiz de Fora, Juiz de Fora, MG, Brasil. Mestre em Direito.

E-mail: geovanafaza@gmail.com
\end{abstract}

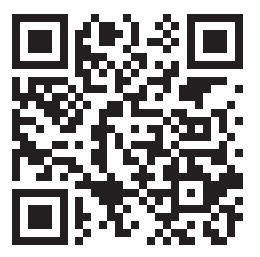

DOI: http://dx.doi.org/10.31512/rdj.v21i39.310

Recebido em: 29.09.2019

Aceito em: 18.07.2020

\begin{abstract}
Resumo: Nas discussóes sobre a insuficiência do processo judicial para resolver todos os tipos de conflitos, emergem os meios consensuais, autocompositivos, como formas de resolução mais colaborativa, participativa, democrática e humanizada, a mobilizar uma diversidade de temas e conhecimentos. O presente estudo tem por objetivo analisar criticamente o processo judicial e a adoçáo de meios consensuais no contexto do tribunal multiportas, a partir dos influxos dos paradigmas democrático e holístico, como métodos adequados a diversas situaçóes, a depender da voluntariedade dos envolvidos e de sua disposiçâo para o engajamento dialógico e colaborativo na construçáo da solução. A análise é feita a partir de teorias sobre o processo, sobre a colaboração como fundamento antropológico e sociológico dos meios consensuais, passando-se para algumas justificativas para a adoção de métodos autocompositivos no paradigma democrático. São levantadas algumas críticas aos meios consensuais, notadamente o fator desequilíbrio de partes e imposição de uma harmonia coerciva. Por fim, busca refletir sobre a figura do tribunal multiportas e a importância da coexistência do modelo adversarial com o consensual. Por ser um campo interdisciplinar de investigaçáo, procurase demonstrar, a partir de uma abordagem crítica e hermenêutica, tomando por base pesquisa bibliográfica, que a adoção do tribunal multiportas tem por fim o fortalecimento dos direitos fundamentais, da democracia e da humanização nos processos de resolução de demandas.
\end{abstract}

Palavras-chave: Processo. Meios Consensuais. Tribunal Multiportas. Justiça.

Abstract: In discussions about the inadequacy of the judicial process to resolve all kinds of conflicts, consensual, self-compelling means emerge as more collaborative, participatory, democratic and humanized forms of resolution, mobilizing a diversity of themes and knowledge. The present 
study aims to critically analyze the judicial process and the adoption of consensual means in the multidoor system context, based on the influx of the democratic and holistic paradigms, as appropriate methods to various situations, depending on the willingness of those involved and their willingness for dialogic and collaborative engagement in building the solution. The analysis is made from theories about the process, about collaboration as an anthropological and sociological foundation of consensual means, moving to some justifications for the adoption of self-compositional methods in the democratic paradigm. Some criticisms are raised about consensual means, notably the factor imbalance of parts and the imposition of a coercive harmony. Finally, it seeks to reflect on the figure of the multidoor court and the importance of the coexistence of the adversarial model with the consensual one. As it is an interdisciplinary field of investigation, we seek to demonstrate, from a critical and hermeneutic approach, based on bibliographic research, that the adoption of the multidoor court aims to strengthen fundamental rights, democracy and humanization in the processes of demand resolution.

Keywords: Process. Consensual means. Multi-door courthouse system. Justice.

\section{Consideraçóes iniciais}

O presente artigo tem por objetivo abordar, com viés crítico, no contexto da metáfora do tribunal multiportas, o processo, como forma heterocompositiva de resolução de conflitos, ao lado dos meios consensuais, autocompositivos, com a intervenção de um terceiro facilitador, independentemente do tipo de litígio. Para tanto, parte-se da análise de algumas características do processo, tais como adversariedade, dogmática jurídica, instrumentalidade, formalismo, heterocomposição, distância entre os entes do processo, para então abordar-se a questáo da mudança paradigmática no trato com os conflitos e a adoção dos meios consensuais.

A mudança paradigmática no direito, decorrente da complexidade da sociedade globalizada, jaz como pano de fundo às reflexóes sobre a necessidade de remodelamento das formas tradicionais e institucionalizadas de se resolver os conflitos judicializados.

Pretende-se aqui contribuir para reflexóes acerca da crescente necessidade de se pensar o processo e os meios consensuais - incluídas a conciliação, a mediação e a justiça restaurativa -, a partir de um viés hermenêutico capaz de aliar a crítica construtiva às convicçóes sobre as potencialidades da realização da justiça. No contexto do tribunal multiportas, cada método de resoluçáo possui seus prós e contras, a depender de uma série de fatores, como o tipo de litígio, a necessidade de se conferir eficácia erga omnes, ou não, à decisão final, os tipos de relaçôes, os aspectos subjacentes ao conflito, entre outros. 
O trabalho inicia-se com revisóes bibliográficas sobre alguns pontos críticos do processo judicial. Em seguida, aborda as principais justificativas para a adoção dos meios consensuais, levando-se em conta alguns entraves. Por fim, tangencia a figura do tribunal multiportas a partir de aportes atinentes à transição paradigmática, de um modelo modernista dependente da competição para outro mais sistêmico e holístico, que compreende a colaboração como fator preponderante nas relaçóes sociais e no tratamento dos conflitos.

Recorre-se ainda a certas críticas sobre a ideologia do consensualismo e da harmonia coerciva, e também sobre aspectos positivos quanto ao fortalecimento da noção de multiportas e sobre a disponibilização aos cidadáos de meios adequados à resolução de seus conflitos.

Do ponto de vista metodológico, trata-se de um trabalho preponderantemente de revisão bibliográfica, que não prescinde do processo de interpretação crítica. A escolha, portanto, recai sobre a teoria hermenêutica-crítica do direito, que oportuniza uma abordagem interdisciplinar do tema. A partir dessa delimitação, espera-se desenvolver uma breve reflexão acerca do processo e dos meios consensuais. A metodologia hermenêutica permite uma abordagem contemporânea, com vistas à reinterpretação dos temas pesquisados sob a luz das necessidades da sociedade contemporânea, em busca da ressignificação das práticas jurídicas.

\section{0 processo judicial, entre críticas e convicçóes}

O processo é uma das mais importantes instituiçóes criadas pelas sociedades para solucionar seus conflitos de forma civilizada. Como produto cultural, o momento histórico, os valores éticos e as crenças influenciam a técnica, a conformação do processo, as regras procedimentais que o moldam, assim como a forma de atuação dos envolvidos na relação processual: autor réu - Estado-juiz. A técnica, em si, é neutra, mas a sua forma de expressão é axiológica, razão pela qual processualistas contemporâneos têm refletido a respeito do fenômeno do formalismovalorativo, repensando a relação jurídica, a jurisdição, o processo e suas técnicas a partir de uma ótica interdisciplinar, integrativa, e por que não dizer holística. Essas questôes, assim pensadas, permitem a verificação dos impactos que as "vertentes políticas, culturais e axiológicas dos fatores condicionantes e determinantes da estruturação e organização do processo" têm sobre os elementos da jurisdição e sobre as ideias de acesso à justiça, conforme defende Alvaro de Oliveira (2008, p. 130).

Luís Guilherme Marinoni (2008, p. 543) também reflete sobre os delineamentos teóricos e pragmáticos que moldam o processo e a relação jurídica processual na contemporaneidade, acentuando a insuficiência do modelo liberal de conceituação da relação jurídica, isso porque no contexto atual, a legitimidade atrela-se à participação efetiva dos envolvidos no procedimento, estando ela relacionada à efetividade e adequação do procedimento ou método de resoluçáo. Essa postura liga-se à ideia de Estado Democrático e à constitucionalização de princípios, que impactam frontalmente o panorama processual. 
A mudança de paradigma, do modelo socializante para o democrático-constitucional, introduz uma flexibilização na aplicação do direito, e, por via de consequência, na atuação de seus operadores, que passam a ter menos foco na segurança e mais na efetividade. Ao passo que a lógica procedimental-instrumental é abrandada, é valorizada a tentativa de se recuperar o valor essencial do diálogo na formação do juízo, da cooperação entre os entes do processo, ou seja, "há de se frutificar pela cooperação das partes como o órgão judicial e deste com as partes, segundo as regras formais do processo", leciona Marinoni (2008, p. 544).

O colóquio deve ser fortalecido, como forma de superar a oposição e o confronto, estimulados pela visão de contraposição entre autor e réu, inerente ao processo, que foi construído e pautado na valorização do contraditório e da dinâmica adversarial e polarizada. No novel contexto, a colaboração passa a ser estimulada como diretiva de uma democracia mais participativa, como exercício mais ativo da cidadania, inclusive no campo da relação processual. Nas palavras de Alvaro de Oliveira (2008, p. 135-136),

a ideia de cooperação além de exigir, sim, um juiz ativo e leal, colocado no centro da controvérsia, importará senão o restabelecimento do caráter isonômico do processo pelo menos a busca de um ponto de equilíbrio. Esse objetivo impóe-se alcançado pelo fortalecimento dos poderes das partes, por sua participação mais ativa e leal no processo de formação da decisão, em consonância com uma visão não autoritária do papel do juiz e mais contemporânea quanto à divisão do trabalho entre órgão judicial e as partes.

A colaboração, o diálogo, a lealdade e o respeito à participação efetiva têm sido estimuladas em diversos setores da sociedade, pautada não somente em teorias sociológicas que a defendem, mas também como produto de pesquisas no campo das ciências biológicas. E o crescente e necessário diálogo entre diversas ciências, que se descortina no século XXI, influencia sobremaneira o direito, como ciência social aplicada, e seus institutos, dentre eles o processo e os demais meios de resolução de conflitos.

A cooperação, a boa-fé e a busca pela consensualidade, inclusive, são consideradas princípios norteadores do direito processual civil, normatizados no Código de Processo Civil de 2015. A exigência de diálogo entre os envolvidos na relação processual, o dever de cooperação entre as partes e a ampliação da boa-fé são vieses que deverão ser observados na releitura do direito contemporâneo. Se a oposição e o confronto dão azo ao concurso de atividades dos sujeitos processuais pautadas na competição, particularidades essas construídas a partir de vícios dogmáticos e positivistas e de ideais liberais, ligados à modernidade, a cooperaçáo traça a linha para a colaboração na construção conjunta da resolução, sendo uma das tônicas do paradigma democrático, no âmbito mais específico do direito, e do paradigma holístico, considerando todas as ciências e a relação ser humano com a sociedade e a natureza.

O fato é que o processo contencioso possui seus limites, sendo, muitas vezes, míope às necessidades humanas mais básicas dos envolvidos, como a apreciaçáo, o reconhecimento e o sentimento de pertencimento, consoante reflete Jacques Comaille (2009, p. 96). Em muitos casos, a brasa que alimenta o conflito continuará a existir e, não raro, poderá desencadear 
outros conflitos, originando demandas-filhotes, ou desdobramentos conflitivos que não foram resolvidos pelo método adversarial. Essa complexa dinâmica de litígios, que se relaciona a espirais destrutivas, a quadros de assimetria de poder, de violência, de relaçóes continuadas e multiplexas, que não se desfazem com a decisão judicial, faz surgir a necessidade de o Estado oferecer aos cidadãos outros meios de resoluçáo de conflitos como opçôes ao processo judicial. Meios cuja plasticidade ou informalidade permitam considerar-se não somente a lide processual, mas que levem em conta relaçóes, aspectos, dinâmicas que influenciem a solução do caso e que, dado os limites objetivos do processo, não seriam passíveis de serem apreciados pelo julgador. Nesse contexto, passa-se a examinar sobre algumas características do processo, enfocando aspectos críticos, à vista do objetivo da presente análise.

O processo, como relação triádica, tradicionalmente é caracterizado por uma distância ontológica entre as partes, de modo a permitir ao juiz proferir uma decisão imparcial, que coloque fim ao litígio. Dessa distância, emerge um ponto crítico: ela impóe um desencorajamento ao contato direto e pessoal entre o corpo adjudicatório (juízes e cortes de justiça), as partes, testemunhas, peritos ou outras fontes de informaçôes, conforme alerta Mauro Cappelletti (1971, p. 848). Trata-se de uma tradição fortemente arraigada no modelo liberal de viés francês, e que vem da distância ontológica entre autor-juiz-réu, sendo também decorrente da figura do juiz passivo, distante e imparcial, que apenas assiste a atividade das partes. O juiz, nesse formato, é chamado a fundamentar sua decisão exclusivamente com base nos registros dos autos, o que leva a uma simplificação da complexidade. Diga-se, uma simplificação binária e polarizada da realidade complexa do conflito: rotula-se, então, a partir de dicotomias - certo x errado; lícito x ilícito; culpado x inocente; falso x verdadeiro; condenado $\mathrm{x}$ absolvido; autor $\mathrm{x}$ réu, $\mathrm{e}$ daí por diante. Nessa postura, há um fechamento de olhos às questóes subjacentes ao conflito e que muitas vezes impactam sua resolução e até os desdobramentos futuros daquela demanda, podendo gerar uma litigiosidade contida.

Nesse sentido, a frieza do processo litigioso e sua instrumentalização levou Luis Alberto Warat a questionar a postura dos profissionais do direito e a pensar sobre a ausência de sensibilidade, e de alteridade, no processo tradicional de resolução de conflitos:

Os operadores do Direito não revelam nenhum excesso de sensibilidade, ao contrário, as formas dominantes de conceber o Direito conseguem formar operadores sem sensibilidade, corpos sem capacidade de relacionar-se sensivelmente com os outros e com o mundo. Os autistas temem um tipo muito particular de escuta, o que eu chamo de escuta alienada ou de uma escuta cega em relação a tudo o que se deveria escutar, que está relacionado com a capacidade de perceber o que o outro emocionalmente reclama. Não escutam as necessidades emocionais do outro senão caem embriagados com seu próprio canto da sereia. [...] os juristas se mostram com uma inquietante incapacidade de escutar os sentimentos das pessoas. Esses sentimentos se encontram encobertos por camadas de representaçốes ideológicas que são escutadas, porém, de um modo tão estridente que impossibilita qualquer outra escuta. Os juristas terminam só escutando, de modo autorreferencial, as vozes e crenças de sua ideologia funcional ou institucional [...]. (WARAT, 2004b, p. 67). 
Essas reflexôes partem da realidade de que o processo é prenhe de vieses ideológicos. Magistrados, advogados, promotores, teóricos partem de concepçóes culturalmente arraigadas na sociedade e as transplantam para sua atuação profissional. Assim, a conhecida crise de alteridade, o distanciamento interpessoal, a ausência de verdadeira escuta, a valorização da competiçáo cada vez mais acirrada são transpostas para a realidade processual, impedindo um contato empático entre os atores do processo, distanciando-os cada vez mais, o que faz acirrar as posturas litigantes e a atuação estratégica baseada em uma racionalidade instrumental, sem preocupaçôes com o outro e que acaba contribuindo para a dinâmica adversarial do perde-ganha.

O iter procedimental formalista, sendo essa outra característica do processo, acaba afastando reais possibilidades de construção colaborativa da solução, inclusive com condução pelo próprio juiz. O afastamento distancia-o dos fatos e dos sentimentos dos envolvidos, valendo, no paradigma liberal e até no socializante, a inércia do julgador espelhada pelo princípio dispositivo. As oportunidades de encontros para a discussão sobre possível composição são exceçôes nesses vieses, servindo, muitas vezes, para cumprir apenas uma formalidade constante nos códigos, como a conhecida audiência de conciliação prevista em muitos ordenamentos. Essas características são abrandadas no modelo democrático contemporâneo.

Mesmo diante das características do modelo tradicional e de algumas inserções procedimentais visando à maior efetividade da prestação jurisdicional, o processo ainda sofre críticas em relação à sua dimensão adversarial e à estreiteza das oportunidades de engajamento dialógico entre os envolvidos. As colocaçôes referentes à formatação da jurisdição condizente com as necessidades democráticas, de maior efetividade dos direitos fundamentais, de maior ligação com a consciência constitucional vigente no pós-II Guerra e de maior flexibilização do processo com a previsão de meios mais adequados a determinados tipos de demandas, não afastam, todavia, a necessidade de observância de um formalismo processual e de uma ritualística, indispensáveis às garantias constitucionais. A técnica e os ritos continuam sendo importantes à segurança jurídica. O que se quer dizer é que a moderna "sacralizaçáo" do processo deve ceder espaço para uma flexibilização das formas em prol de objetivos maiores a serem perseguidos pela atuação jurisdicional, especialmente aqueles que servem à dignidade da pessoa humana consciente das novas potencialidades da justiça.

Outro fator a destacar é que o processo resolve o recorte do conflito que é levado ao conhecimento do juiz, deixando de lado questóes subjacentes que podem impulsionar a dinâmica conflitiva e que, se não resolvidas a contento podem desencadear novos conflitos e, assim, novas açôes. Isso ocorre, muito, por conta da tradicional concepção de que "para a cultura do litígio a única realidade que importa é a que está no processo", conforme reflexão de Warat (2010, p. 3). O magistrado, não obstante os abrandamentos contemporâneos, não pode sair da realidade do processo para buscar razões exteriores visando à fundamentação da sua decisão, prendendo-o dentro do "labirinto processual" (WARAT, 2010, p. 3). 
A razão processual é uma razão instrumental e estratégica, muitas vezes afastada "das evidências dadas pela realidade” (WARAT, 2010, p. 26). Em diversos casos, a lide não permite ao julgador vislumbrar o que está 'por baixo', ou 'por trás' daquele recorte simplificado e sobre o qual o Estado-juiz deverá se pronunciar. São as chamadas questóes subjacentes, verdadeiros interesses que retroalimentam o conflito e que podem estar ligados às suas verdadeiras causas.

O processo simplifica o conflito, sem fotografar com fidelidade a realidade na qual inserido e que o constitui. Ele o objetiva fazendo acreditar que o reflete como se fosse uma cópia reprográfica do panorama real, plasmando, de certo modo, uma ilusão jurídica, em alusão a Warat (2010). A lógica do processo é centrada em uma discussão argumentativa, sendo comum a barganha, na qual cada um procura explorar os pontos fracos do adversário, pretendendo alcançar a maior vantagem cedendo o mínimo possível.

O processo busca uma verdade e, nessa perseguição, pode reproduzir a violência. E não importa tentar "distinguir entre verdade como correspondência fática e verdade como interpretação, ambas são manipuladas. Ninguém sabe o que vai acontecer. Ninguém pode predizer o real, ele é imprevisível” (WARAT, 2004a, p. 17-18). Warat pensa deste modo por considerar outras gramáticas que permeiam o direito, "gramáticas tão diferentes do normativismo" (WARAT, 2010, p. 59) por serem quase incompreensíveis, justamente porque estão fora do "prato" do normativismo racionalista, da objetividade racional para a fundamentação argumentativa do direito, conforme metáfora empregada pelo jusfilósofo argentino.

Parte-se, então, da premissa de que não se pode ter conhecimento completo, sendo a parcialidade da informação condição de enfrentamento da teoria da decisão no processo, civil ou penal. O processo constrói realidades passadas na e pela linguagem, por meio de informaçóes invocadas, trazidas pelas partes, que lhes dão os sentidos possíveis. Nesse ponto, os argumentos dos agentes processuais ganham relevo, e diante de suas estratégias, as informaçóes lhes podem ser favoráveis ou desfavoráveis.

$\mathrm{Na}$ contramão dessas ponderaçóes acerca do processo litigioso, a autocomposiçáo emerge no campo processual como opçáo ao cidadão, mas sem o condão de efetuar cortes temporais ou de buscar verdades únicas ou de trabalhar a preponderância de determinada informação. Ela tem o papel de colocar as partes em contato para que possam, por elas mesmas e auxiliadas por terceiro, trabalhar a comunicaçáo transformadora, para, assim, tentar reconstruir o espaço dialógico rompido pelo conflito.

Ainda na esteira dos limites do processo contencioso, Owen Fiss (1984), professor da Universidade de Yale, ponderou que as cortes de justiça são consideradas como a institucionalização do estranho e a adjudicação é vista como o processo pelo qual o estranho exerce o poder. Os envolvidos recorrem ao Estado-juiz para resolver sua disputa e, em regra, essa alternativa já sinaliza que houve uma ruptura na relação social entre as partes. Para o professor, os defensores da "Alternative Dispute Resolution" reconhecem esse fato, entretanto, esperam que os envolvidos 
sejam capazes de chegar a um acordo antes que o juiz decida a questão, de forma impositiva e verticalizada.

Não obstante as críticas direcionadas ao processo, é necessário reconhecer sua importância como meio de estabilização social e resolução de uma gama considerável de litígios, embora padeça de insuficiências frente a diversos tipos de conflitos ou então a alguns tipos de relações sociais, a depender da disposiçáo das partes e sua predisposição para aceitar um closure da disputa pela resolução heterocompositiva e, assim, seguir adiante na vida.

A imposição de uma decisão heterônoma e coercitiva, que deverá ser cumprida independentemente da vontade dos envolvidos, pode ser nefasta pela violência simbólica que pode representar e pela forma adversarial como é construída. Essas consequências não são atribuídas ao Poder Judiciário, mas sim à própria natureza do processo heterocompositivo. Heterocompositivo porque as partes contrapostas, não conseguindo se ajustar, entregam suas divergências a um terceiro imparcial, o juiz, que tem o dever legal de resolver o conflito. Segundo Humberto Theodoro Júnior (2015, p. 69-70), o processo

é um ambiente no qual prevalecem interesses não cooperativos de todos os sujeitos processuais. $\mathrm{O}$ juiz imerso na busca por otimização numérica de seus julgados e as partes (e seus advogados) no âmbito de uma litigância estratégica (agir estratégico) com a finalidade de obtenção de êxito. Esta patologia de índole fática não representa minimamente os comandos normativos impostos pelo modelo constitucional de processo, nem mesmo os grandes propósitos que o processo, como garantia, deve ofertar. Ao se partir dessa constatação cabe ao direito, dentro de seu pressuposto contrafático, ofertar uma base normativa que induza um comportamento de diálogo genuíno no qual estes comportamentos não cooperativos sejam mitigados. Isto induz à assunção do processo como um locus normativamente condutor de uma comunidade de trabalho, na qual todos os sujeitos processuais devam atuar em viés interdependente e auxiliar, com responsabilidade, na construção dos pronunciamentos judiciais e em sua efetivação.

Ainda com relação ao modelo adjudicatório, destaca-se lição de Judith Resnik (1995, p. 227), para quem a adjudicação é relida como um processo eficaz de resolução de disputas projetado para ser a ultima ratio. Com efeito, há de ser utilizado quando outros meios à disposiçáo não forem indicados como os mais adequados para o caso, ou seja, mais condizentes à dignidade da pessoa humana e à busca da justiça.

Concluindo o pensamento sobre o processo, deve ser ressaltado que, neste momento histórico, as ideias correlatas ao paradigma democrático, inserindo-se aí a remodelagem da dimensão dos direitos fundamentais e dos princípios processuais, devem ser trazidas para a estrutura institucional de composição de litígios. Daí o surgimento de outros meios como opçôes ao processo judicial que sejam caracterizados por maior consensualidade, protagonismo no desenho da solução para o conflito, não adversariedade, informalidade, confidencialidade, possibilidade de consideração das questôes subjacentes, envolvimento de redes de pertinência, abordagens multidisciplinares etc. 


\section{Os meios consensuais, entre convicçóes e críticas}

A cooperação é considerada um dos fundamentos antropológicos e sociológicos dos meios consensuais. $\mathrm{O}$ ideário cooperativo liga-se à necessidade de humanização dos procedimentos de resolução de conflitos, que passam a ser guiados por ideais de fraternidade, de fortalecimento da alteridade e do reconhecimento mútuo, levando à conscientização de que o sistema processual não tem objetivos puramente técnicos, mas escopos que desbordam da instrumentalidade processual e da mera realização do direito material.

No horizonte da atual sociedade complexa, cujos problemas são interconectados e interdependentes, faz-se necessária a adoção de meios de resolução que possam abarcar a complexidade dos dissensos e a exigência maior de participação dos interessados e colaboração na construção das soluçôes. Essa mudança de paradigmas se faz sentir em todos os campos do conhecimento humano: nas ciências naturais e também sociais. No campo do direito, e aqui pode-se falar em um "novo direito", as mudanças impactam na forma de se pensar o Estado e suas áreas de intervenção, na forma de delineamento da cidadania, no trato dos cidadãos e também nas formas de se administrar os litígios. Nesse contexto é que se inserem a conciliação, a mediação e a justiça restaurativa como formas mais colaborativas e participativas, sendo que na mediação e na restaurativa são levadas em conta as relaçôes e contextos subjacentes, os ambientes interno e externo do conflito, possibilitando albergar situaçóes que impactam a dinâmica conflitiva, e que servem ora de combustível ora de oportunidade de solução.

Os meios consensuais facilitam a instauração da comunicação rompida entre as partes em razão da posição antagônica instituída pelo litígio, uma vez que facilita a expressão do dissenso, definindo um veículo que possa administrar a discordância e chegar a um entendimento comunicativo, conforme defende Fabiana Spengler (2007, p. 343). Ao se buscar ganhos mútuos a partir da cooperaçáo e da ideia de que os “jogadores” não possuem estritamente interesses opostos, promove-se a autocomposição de interesses que podem ser coadunados, principalmente em casos de relaçóes continuadas.

Os meios autocompositivos também focam na autonomização dos litigantes na busca por uma resposta consensuada e compartilhada, com fundamento em estruturas de bases de diálogos transformadores, de práticas comunicativas não-violentas, de narrativas e da escuta profunda, favorecendo inclusive o "direito fraterno" (Cf. COLET, 2009), fundado no princípio de nossa comum humanidade. O principal desafio da autocomposição não é só resolver o conflito, mas encontrar mecanismos que possibilitem uma convivência comunicativamente pacífica, a inclusão, o reconhecimento mútuo e um possível encerramento construtivo para o conflito, para que as partes possam seguir com suas vidas. Se é pelo diálogo que surgem as bases do conflito, então o diálogo pode ser a melhor opção para tratar as realidades conflitantes, reduzindo o potencial de hostilidade e agressão. 
Os meios consensuais se lastreiam na aproximação dos envolvidos, no seu engajamento, razão pela qual se entende que não deve haver imposição coercitiva para sua adoção, mas sim liberdade de escolha, sem a qual o engajamento colaborativo resta prejudicado, minando a confiança e a reciprocidade. Owen Fiss (1984), já na década de 1980, demonstrava sua preocupaçáo ao reafirmar que nos meios consensuais as partes podem ser pressionadas a aceitar acordos, seja como política dos tribunais, seja em razão da atuação do facilitador. Nesse ponto, é importante salientar que os meios consensuais devem ser lastreados em indicadores de qualidade e não de quantidade, de colocaçáo de fim ao processo, pois senão haveria um estímulo, mesmo que indireto, à realização de pressão por parte do facilitador para que as partes alcancem um acordo.

O terceiro facilitador deverá, por meio de técnicas e abordagens apropriadas, estimular a cooperação e o diálogo construtivo. Contudo, deverá fazer mais do que uma referência a um procedimento cooperativo, solidário, de mútua composição, sendo de suma importância que traga para o campo da resolução a ideia de alteridade, que diz respeito a uma possibilidade de transformar o conflito e de deixar-se transformar por ele, graças à possibilidade assistida de poder olhar a partir do olhar do outro, e colocar-se em seu lugar para entendê-lo, bem como a si mesmos. É a alteridade, a outridade, como possibilidade de transformação do conflito, produzindo a diferença com o outro e revalorizando o outro. Vistos por essas lentes, os meios consensuais podem ser considerados a partir da ética da alteridade: da recuperação do respeito e do reconhecimento da integridade e da dignidade. Reflete Warat (2004b, p. 55) que

Essa mudança de lentes ao olhar para os conflitos traz uma nova concepção dos mesmos. As divergências passam a ser vistas como oportunidades alquímicas, as energias antagônicas como complementares, e o Direito como solidariedade. As velhas lentes que fragmentavam, classificavam e geravam distâncias vão para a lixeira. Começamos a entender que cada homem não é uma mônada isolada, que não são fragmentos sem conexâo. Cada um é interdependente e produto forçado das interaçôes. A sociedade é unicamente produto da complexidade desses.

Nessa ótica, a busca por interesses próprios pode muito bem se coadunar com a perspectiva da colaboração, principalmente quando em questão relaçôes continuadas. A alteridade e a consideração da dignidade do outro podem coexistir com a perseguição por interesses próprios. E serão elas que permitirão uma atuação colaborativa na busca por ganhos mútuos, mesmo que cada envolvido esteja perseguindo seus próprios interesses. Ainda, paralelamente à ética da alteridade, deve-se pensar a outridade no sentido de captar o outro: é necessário captar a alteridade ética do outro e a honestidade que trata de se instalar em sua outridade, independentemente de quem seja o outro (WARAT, 2004b). É imperioso, portanto, forçar essa noção de alteridade, tão relegada pelo mecanicismo cartesiano do século XVII ao século XX, consoante pondera Fritjof Capra (CAPRA; LUISI, 2014, p. 14), pela modernidade egocêntrica, reducionista e manipuladora, que acabou diluindo o outro em sua alteridade (WARAT, 2004b, p. 145). 
Assim, o paradigma sistêmico ou holístico, que desponta no século XXI como horizonte interpretativo das relaçóes sociais, impacta as formas de resolução de conflitos, trazendo para seu contexto uma visão sistêmica, que não é linear. Vale trazer à baila, nesse ponto, reflexão de Capra e Luisi (2014, p.15) acerca da visão sistêmica, levada em conta na análise das técnicas autocompositivas:

Uma característica central da visão sistêmica é sua não linearidade: todos os sistemas vivos são redes complexas - isto é, são, em um alto grau, não lineares; e há incontáveis interconexôes entre as dimensôes biológicas, cognitivas, sociais e ecológicas da vida. Desse modo, um arcabouço conceitual que integre essas muitas dimensōes sem dúvida refletirá a não linearidade inerente à vida.

Por conseguinte, parte-se da premissa da não linearidade inerente à vida, pode-se transpor essa noção para o campo dos conflitos. Eles também seguem essa não linearidade, que náo é considerada pelo processo judicial, mas que pode ser considerada na seara dos meios consensuais, principalmente em razão de sua informalidade e dos princípios interdisciplinares que os guiam, que possibilitam que consideraçôes acerca das dimensôes biológicas, cognitivas, sociais e ecológicas da vida sejam consideradas, permitindo uma soluçáo igualmente sistêmica, que contribua para uma estabilização e uma pacificação mais duradoura.

Colocada nessa moldura, as finalidades primordiais das técnicas autocompositivas são: responsabilizar os conflitantes pelo tratamento do litígio que os une e devolvê-los o protagonismo na construção das soluçóes, podendo-se afirmar que os meios consensuais podem ser fundamentados, em síntese, pela ética da alteridade, pela visão sistêmica que considera a interconexão e interdependência dos fenômenos, naturais e sociais, pelo objetivo de se aparar as arestas e divergências com vistas à compreensão das emoçôes reprimidas, pela comunicação direcionada ao entendimento e atenta aos interesses das partes, e pelo reconhecimento mútuo.

As técnicas autocompositivas buscam a substituição da negociação distributiva, pela resolução cooperativa e integradora dos problemas. Ao passo que, pela lógica do processo, centrada em uma discussão argumentativa, é comum a barganha, na qual cada um procura explorar os pontos fracos do adversário, pretendendo alcançar-se a maior vantagem cedendo o mínimo possível. Já na autocomposição, os indivíduos são encorajados a ouvir e a entender os pensamentos e sentimentos uns dos outros, sendo estimulados a gerar opçóes de ganhos mútuos e a trabalhar juntos para se chegar a uma resposta satisfatória para ambos.

Ainda, vale frisar que a autocomposição é um procedimento democrático também porque rompe e dissolve os marcos de referência da certeza, determinados pelo conjunto normativo que privilegia a verdade formal e a busca por uma verdade material desde que limitada à lide. Ademais, acolhe a desordem e considera o conflito como possibilidade positiva de evolução social. É também democrática quanto ao fundamento da relação de um com o outro, apostando na diferença entre o tratamento das demandas de maneira judicante, para uma forma compartilhada e convencionada que tenha por base um direito inclusivo e fraterno. 
Cappelletti (1994,p. 246-247) salienta, também, que a demanda por meios autocompositivos se liga à ideia de que eles podem ser menos custosos e mais rápidos, ao contrário do processo tradicional, eis que um método de $A D R$ pode ser preferível porque provê um resultado mais célere e barato, não afastando de todo o processo, podendo ser um 'plus'. Outro elogio à $A D R$ diz respeito ao seu potencial de gentileza, quando contrastado com a adversariedade e confronto associados à adjudicação. A ADRé percebida como mais amigável, flexível e melhor do que as trocas de incivilidade que muitas vezes caracterizam o litígio, isso porque os meios consensuais oferecem espaço para que sejam adaptados ao tipo de litígio visando a produzir resoluçóes duradouras sem fortalecer a mágoa e o rancor, porque centrados na cooperação.

Além dos argumentos apresentados que justificam a adoção dos meios consensuais, muitos defensores da chamada ADR (Alternative Dispute Resolution) ainda são levados a apoiálos e a exaltar a ideia de autocomposição de forma mais irrestrita por considerar o processo moroso, ineficiente e caro. Não raro, também defendem que, por exemplo, brigas entre vizinhos que chegaram a um impasse não devem ser levadas a um tribunal, postura que deixa claro o entendimento de que o Judiciário náo deveria ser o destino de demandas que poderiam ser resolvidas pela boa vontade e diálogo entre os indivíduos.

Tendo em vista as benesses na adoção dos meios consensuais, os entusiastas não devem fechar os olhos às possíveis críticas, certamente emergentes de diversas dificuldades, relegando, assim, os pontos frágeis à sombra. Nem tudo são flores na $A D R$. Uma questáo relevante a ser considerada é que os meios consensuais podem se deparar com sérios desequilíbrios de poder, que configuram fator de peso nas dinâmicas negociais, podendo, inclusive, contribuir para a realização de acordos injustos, demasiadamente onerosos para uma das partes. De fato, os meios lastreados em processos negociais tratam do acordo como uma antecipaçáo do resultado do julgamento e pressupóem que seus termos sejam um produto das previsóes das partes sobre esse resultado. Em verdade, os modelos assentados em acordo e a ele direcionados (como os settlement-oriented mediation, a conciliação) são adotados muitas vezes em função dos recursos disponíveis para cada parte financiar o litígio, e esses recursos são frequentemente distribuídos de forma desigual.

As históricas assimetrias entre os litigantes permeiam as reivindicaçóes de trabalhadores contra grandes corporações; as dos cidadãos pleiteando reparações de danos em decorrência de açóes de uma grande empresa; as lides entre cidadáos e o Estado; entre Estados soberanos em situaçóes de desenvolvimento econômico-social díspares. Nestes casos, as desigualdades de distribuição de recursos financeiros entre os envolvidos afeta, invariavelmente, o processo de negociação, e o acordo pode tornar-se um desacordo, com uma concepção de justiça que visa a tornar a riqueza ou pobreza das partes irrelevante.

Nessa senda, Owen Fiss (1984, p. 1076-1077) afirma que as disparidades de recursos entre as partes podem influenciar o acordo de três maneiras. Primeiramente, a parte mais pobre pode ser menos capaz de coletar e analisar as informaçóes necessárias para prever o resultado do 
litígio, podendo ser prejudicada no processo de barganha. Em segundo lugar, é mais dificultoso para a parte mais frágil precisar os danos que uma ação judicial pode acarretar ou, então, os prováveis ganhos que dela poderá obter, o que faz com que procure resolver pelo acordo, por ser um caminho de aceleração da solução, mesmo que ela perceba que iria receber menos agora do que no julgamento. Owen diz que um autor em posição de fragilidade, pobre ou indigente, pode, inclusive, ser explorado por um réu rico porque sua necessidade é tão grande que o réu poderá forçá-lo a aceitar uma soma menor do que receberia em um julgamento (FISS, 1984, p. 1076).

Em terceiro lugar, destaca Fiss (1984, p. 1076-1077) que a parte mais pobre pode ser forçada a resolver porque ela não tem os recursos para financiar o litígio, para cobrir suas próprias despesas projetadas, como o tempo de seu advogado, ou as despesas que seu oponente pode impor através da manipulação de mecanismos processuais. Mesmo com a assistência judiciária gratuita, é provável que o litigante necessitado de recursos financeiros se sinta impelido a aceitar um acordo com grande deságio, só pelo simples fato de precisar imediatamente da quantia. Isso pode parecer que o acordo o beneficia, permitindo-lhe evitar os custos do litígio, que também são psicológicos, e não apenas materiais. No entanto, a parte economicamente mais frágil na demanda é vítima dos custos do litígio, mesmo com a justiça gratuita, e esse desequilíbrio se reflete no acordo, que acaba deixando a justiça substancial de lado em prol de uma finalizaçáo mais célere e economicamente mais atraente.

Esses apontamentos também foram feitos pela antropóloga norte-americana Laura Nader, ao analisar como os desequilíbrios de poder, o poderio econômico, as disparidades sociais, intelectuais e culturais podem desaguar em acordos injustos e desequilibrados. Para Laura Nader (1994, p. 7), as negociaçóes acabam sendo uma espécie de "ferramenta hegemônica" que estabelece uma arena privilegiada para a imposiçâo de valores e de interesse estatal sobre as comunidades ou os cidadãos. Ela diz que a harmonia coerciva das últimas décadas foi uma forma de controle poderoso, exatamente devido à aceitação geral da harmonia como benigna. Para a antropóloga, a história das condiçôes que determinam as preferências na resolução das disputas são compromissos móveis que geralmente envolvem desequilíbrios de poder (NADER, 1994, p.7). Com esse entendimento, Nader destaca que aqueles que detêm maior poder de barganha, poder econômico ou hegemonia tendem a ganhar em processos negociais, seja em razão da expertise, das alternativas à não realização do acordo, ou por outros fatores, concluindo, a partir de diversos casos por ela examinados, que "a regra é que a parte mais fraca vá em busca da lei e a mais forte prefira negociar" (NADER, 1994, p. 10). Owen Fiss (1984) também reforça esse ponto, argumentando que o método conhecido como o "settlement-oriented" ou conciliação, que é focado no acordo, se baseia na barganha, aceitando desigualdades de riqueza como um componente integral e legítimo.

Ressalta-se, todavia, que essas constatações não podem nublar o potencial dos meios autocompositivos em contribuir para o acesso mais adequado e efetivo à justiça. Ao contrário, 
esses argumentos devem auxiliar na moderação das influências das desigualdades distribucionais, principalmente nos modelos orientados ao acordo.

Por conseguinte, conclui-se, aqui, que há prós e contras quanto aos meios consensuais, sendo necessários debates e pesquisas acerca do tema, de modo a enfraquecer o processo de controle cultural, que pode impor uma ideologia da harmonia coerciva (NADER, 1995). Por isso os meios adequados a determinados tipos de demandas devem ser estimulados na medida e de forma a respeitar a voluntariedade e a autonomia das partes e, principalmente, a robustecer os direitos humanos, como ferramentas de sua garantia.

\section{Tribunal Multiportas: meios consensuais como opção}

$\mathrm{Na}$ ponderação entre as críticas e as convicções em relação ao processo judicial e aos meios consensuais, defende-se aqui que a autocomposição deve ser considerada como opção à acomodação dos meios de resolução às demandas conflitivas e subjetivas das partes, e como necessidade de absorver o protagonismo exigido pelos contornos da cidadania contemporânea, ativa, participativa, pautada em maior autonomia dos sujeitos, em todas as esferas. A adequação do meio de resoluçáo ao tipo de demanda parte da busca pela tutela dos direitos tempestiva, efetiva e também condizente ao direito que se pretende e à inclinaçáo das partes em aceitar uma abordagem dialógica.

Com esses vieses, a justiça estatal imperativa dá espaço para a aplicação da justiça coexistencial, nas palavras de Didier e Zaneti (2018, p. 39), uma “mending justice (uma justiça capaz de remendar o tecido social), focada na pacificação e na continuidade da convivência das pessoas, na condição de indivíduos, comunidade ou grupos envolvidos”. O que não quer dizer que o modelo processual tradicional não seja adequado e que a adjudicação deva ser congelada, ou que os meios consensuais sejam sempre mais eficientes. Ao contrário, o que se defende é que, ao lado dos modelos judiciais tradicionais, a reorientação do sistema de jurisdiçáo deve acomodar as demandas contemporâneas, oferecendo aos cidadãos opções de métodos para a resoluçáo delas. Assim, o núcleo e o escopo do modelo adjudicatório devem ser preservados para aquelas demandas que de fato necessitam de uma coercibilidade, do peso da mão do Estado ou de uma eficácia da decisão que seja erga omnes ou que gere precedentes.

É nesse horizonte que o tribunal multiportas, ou ainda a expressão anglo-saxã multidoor courthouse, abre-se à expectativa social de maior participação e inclusão do cidadão na condução da solução de seus litígios. $\mathrm{O}$ formato de múltiplas portas liga-se ao incentivo à autonomia, maior participação e emancipação, que se relacionam, hodiernamente, à ideia de justiça substantiva e justiça cidadá, superando a simples distributividade e a ideia de retribuição secularmente a ela ligada. A própria ideia de multiportas remete às diversas alternativas que devem ser estabelecidas em prol do jurisdicionado, como opçóes às quais ele pode recorrer voluntariamente, se entender ser o melhor e mais adequado meio para o acerto de sua controvérsia. 
A análise particularizada das demandas ajuizadas é necessária: avalia-se o caso concreto, suas características e contornos e normas envolvidas, e também a disposição dos envolvidos para um engajamento dialógico. Isso porque os métodos consensuais do tribunal multiportas exigem uma imersão em um processo discursivo, de forma democrática e cooperativa, que depende de disposição íntima das partes em resolver seus conflitos de forma colaborativa. Por isso, o diálogo constante entre os meios consensuais e o meio adjudicatório deve acontecer. Pontua-se, aqui, que existem modelos em que as formas consensuais constituem verdadeiras estradas vicinais ao lado do processo tradicional, obstando seu andamento enquanto os envolvidos não recorrem ao método autocompositivo, e também modelos nos quais esses meios são opções, antes ou durante o processo, não estando os envolvidos obrigados a trilhar esses caminhos. Nesses casos, muitas vezes, as partes podem se valer da autocomposiçáo antes do processo ou durante ele, inclusive após o encerramento do processo de conhecimento, durante a fase de execução.

A adoção da ideia multiportas requer empenho dos tribunais em capacitar profissionais de diversas áreas, disponibilizar espaço adequado e instrumentos para o atendimento das partes, administrar programas e acompanhar sua eficácia, entre outros. Por isso é importante mapear e pensar essa mudança de paradigma, tendo no horizonte as discussóes a respeito das resistências, desinteresses e até hostilidades em relação à $A D R$ no tocante a seu potencial de responder a diversos tipos de disputas.

Esse potencial deve ser reforçado para evitar-se manipulações desses meios com objetivo utilitarista de somente colocar fim célere ao processo e reduzir custos. Considerações sobre sua funcionalidade não devem ser centradas tão só na redução da morosidade e dos acervos, mas sim na satisfação dos jurisdicionados, na qualidade dos serviços e na potencialidade de redução da litigiosidade remanescente, por possibilitar um olhar mais profundo para o conflito, o empoderamento e o reconhecimento mútuo, fatores dificilmente mensuráveis. Qualquer formatação do tribunal multiportas deve levar em conta o viés teleológico dos meios consensuais, qual seja, contribuir para uma verdadeira pacificação e robustecimento da justiça cidadã, e não apenas para por fim ao processo.

\section{Consideraçóes finais}

A nova era do tribunal multiportas certamente traz extensas modificaçôes para diversos sistemas judiciais. Seus benefícios são diversos, principalmente se for considerada a correlação sinérgica entre os diferentes meios, de modo a propiciar aos jurisdicionados diversas opçóes, nas quais poderá haver um método mais adequado ao tipo de conflito e à disposição das partes do que outros. Os meios consensuais e o processo devem ser instrumentos de realização da justiça objetiva e substancial. A promoção da conciliação, da mediação e da justiça restaurativa passa, então, a ser vista como uma sábia política social, como vias vicinais ao processo tradicional, com potencial para melhorar a qualidade das resoluçóes dos conflitos, sem se recorrer a defesas calcadas na eficiência ou redução de atrasos. 
Não obstante, o olhar funcional para os meios deve levar em conta a sua inserção em um contexto social amplo, que demanda transformações na forma de administração dos conflitos com o fim de impactar o ranço de litigiosidade que acomete a sociedade contemporânea. Eles se inserem em um contexto de fortalecimento de uma postura mais colaborativa e pacífica, e, ainda, demandam uma mudança de foco dos profissionais do direito: de competidores estrategistas para colaboradores em prol dos interesses reais dos clientes. Cuida-se, pois, de uma humanização no trato dos conflitos.

Mas, reconhecendo os pontos fortes dos meios consensuais e os limites do processo adversarial frente à função precípua da jurisdição, que é a pacificação social, uma leitura que se deve fazer é que de modo algum um deve ser considerado superior ao outro. Eles são diferentes, e, cada um a seu modo, adequado a determinado tipo de demanda e à disposição das partes. Os meios consensuais, portanto, não devem ser vistos como panaceia para o problema da litigiosidade crescente e latente. São abordagens diferentes, não uma necessariamente melhor do que a outra.

Pode-se afirmar que a sociedade contemporânea assiste à emergência de uma nova cultura jurídica, mais democrática, emancipatória e cidadã. Parte-se, desse modo, para o reconhecimento, pelo direito, de métodos participativos, ao lado do processo, como outras portas para o acesso formal e substancial à justiça, fortalecendo a função estabilizadora de expectativas sociais por meio da garantia de um sistema jurídico democrático e efetivador dos direitos humanos. A lente deve ser a de adequação e não de superioridade de um procedimento sobre o outro. Conclui-se, então, que os meios consensuais são complementares às aspirações de efetividade do modelo adjudicatório, sem que sejam considerados uma justiça de segunda mão (second-hand justice).

\section{Referências}

CAPPELLETTI, Mauro. Os métodos alternativos de solução de conflitos no quadro do movimento universal de acesso à justiça. Revista de Processo, Sáo Paulo, v. 74, p. 82-97, abr./jun. 1994.

CAPRA, Fritjof; LUISI, Pier Luigi. A visão sistêmica da vida: uma concepção unificada e suas implicaçóes filosóficas, políticas, sociais e econômicas. São Paulo: Cultrix, 2014.

COLET, Charlise Paula. A valorização do ser humano a partir de matrizes teóricas do direito fraterno e da justiça restaurativa: o tratamento de conflitos como forma de exercício da cidadania. Revista Direito e Justiça - Reflexóes Sociojurídicas, ano IX, n. 12, p. 49-70, 2009.

COMAILLE, Jacques. O Modelo de Janus da regulação jurídica. O carácter revelador das transformaçóes do estatuto político da justiça. Revista Crítica de Ciências Sociais, n. 87, p. 95-119, 2009. Disponível em: https://journals.openedition.org/rccs/1457. Acesso em: 03 jun. 2018. 
DIDIER JR., Fredie; ZANETI JR., Hermes. Justiça Multiportas e tutela adequada em litígios complexos. In: DIDIER JR, Fredie (coord.). Grandes Temas do Novo CPC. Salvador: Jus Podivm, 2018.

FISS, Owen. Against Settlement. The Yale Law Journal, v. 93, n. 6, p. 10731090, 1984. Disponível em: http://digitalcommons.law.yale.edu/cgi/viewcontent. cgi?article=2206\&context=fss_papers. Acesso em: 17 jun. 2018.

MARINONI, Luiz Guilherme. Da Teoria da Relação Jurídica Processual ao Processo Civil do Estado Constitucional. Cadernos da Escola de Direito e Relaçôes Internacionais da UniBrasil, v. 1, n. 6, p. 275-306, jun./dez. 2006. Disponível em: http://revistas. unibrasil.com.br/cadernosdireito/index.php/direito/article/view/440/419. Acesso em: 03 abr. 2019.

NADER, Laura. Controlling Processes. 1995. Disponível em: http://digitalassets.lib. berkeley.edu/anthpubs/ucb/text/kas077-002.pdf. Acesso em: 16 out. 2018.

NADER, Laura. Harmonia coerciva: a economia política dos modelos jurídicos. 1994. Disponível em: http://www.anpocs.org.br/portal/publicacoes/rbcs_00_26/rbcs26_02. htm. Acesso em: 29 set. 2018.

OLIVEIRA, Carlos Alberto Alvaro de. O formalismo-valorativo no confronto com o formalismo excessivo. In: JÚNIOR DIDIER, Fredie (coord.); JORDÃO, Eduardo Ferreira (coord.). Teoria do Processo: Panorama doutrinário mundial. Salvador: Editora Jus Podivm, 2008.

RESNIK, Judith. Many Doors? Closing Doors? Alternative Dispute Resolution and Adjudication. The Ohio State Journal on Dispute Resolution, v.10, n. 2, p. 212-265, 1995. Disponível em: http://digitalcommons.law.yale.edu/fss_papers/894. Acesso em: 15 abr. 2019.

SPENGLER, Fabiana Marion. O Estado-jurisdição em crise e a instituição do consenso: por uma outra cultura no tratamento de conflitos. 2007. 476 f. Tese. Programa de PósGraduação em Direito da Universidade do Vale dos Sinos, São Leopoldo, 2007.

THEODORO JÚNIOR, Humberto et al. Novo CPC Fundamentos e Sistematização Lei 13.105/2015. Rio de Janeiro: Forense, 2015.

WARAT, Luis Alberto. A rua grita Dionísio. Direitos humanos da alteridade: surrealismo e cartografia. Lumen Juris: Rio de Janeiro, 2010.

WARAT, Luis Alberto. Territórios desconhecidos: a procura surrealista pelos lugares do abandono do sentido e da reconstrução da subjetividade. Florianópolis: Fundação Boiteau, 2004a.

WARAT, Luis Alberto. Surfando na pororoca: o ofício do mediador. Florianópolis: Fundação Boiteux, 2004b. 